\title{
ERCC1 as a Predictive Marker for FOLFOX Chemotherapy in an Adjuvant Setting
}

\author{
Chee Young Kim, Sang Hyuk Seo, Min Sung An, Kwang Hee Kim, Ki Beom Bae, Jin Won Hwang ${ }^{1}$, \\ Ji Hyun Kim ${ }^{1}$, Bo Mi Kim², Mi Seon Kang ${ }^{2}$, Min Kyung Oh³ ${ }^{3}$ Kwan Hee Hong \\ Departments of Surgery, ${ }^{1}$ Internal Medicine, and ${ }^{2}$ Pathology, and ${ }^{3}$ Clinical Trial Center in Pharmacology, Inje University Busan Paik Hospital, \\ Inje University College of Medicine, Busan, Korea
}

Purpose: The purpose of this study was to identify the excision repair cross-complementation group 1 (ERCC1) as a predictive marker for FOLFOX adjuvant chemotherapy in stages II and III colon cancer patients.

Methods: A total of 166 high risk stages II and III colon cancer patients were retrospectively enrolled in this study, and data were collected prospectively. They underwent a curative resection followed by FOLFOX4 adjuvant chemotherapy. We analyzed ERCC1 expression in the primary colon tumor by using immunohistochemical staining. The oncological outcomes included the 5-year disease-free survival (DFS) rate. The DFS was analyzed by using the Kaplan-Meier method with the log-rank test. A Cox proportional hazard model was used for the prognostic analysis.

Results: ERCC1-positive expression was statistically significant in the older patients $(\mathrm{P}=0.032)$. In the multivariate analysis, the prognostic factors for DFS were female sex $(\mathrm{P}=0.016), \mathrm{N}$ stage $(\mathrm{P}=0.009)$, and postoperative carcinoembryonic antigen level $(\mathrm{P}=0.001)$, but ERCC1 expression was not a statistically significant prognostic factor for DFS in the univariate analysis $(\mathrm{P}=0.397)$. The 5 -year DFS rate was not significantly associated with the ERCC1 expression in all patients $(\mathrm{P}$ $=0.396)$ or with stage III disease $(\mathrm{P}=0.582)$.

Conclusion: We found that ERCC1 expression was not significantly correlated with the 5-year DFS as reflected by the oncologic outcomes in patients with high-risk stages II and III colon cancer treated with FOLFOX adjuvant chemotherapy.

Keywords: Colon neoplasms; FOLFOX; ERCC1

\section{INTRODUCTION}

Colorectal cancer is the second and third most common cancer among Korean men and women, respectively [1]. The $2013 \mathrm{Na}$ tional Comprehensive Cancer Network guidelines recommended adjuvant FOLFOX or XELOX chemotherapy for patients with high-risk stages II and III colon cancer after surgery [2]. The MOSAIC (Multicenter International Study of Oxaliplatin/5-Fluoro-

Received: May 9, 2015 Accepted: June 18, 2015

Correspondence to: Ki Beom Bae, M.D.

Department of Surgery, Inje University Busan Paik Hospital, Inje University

College of Medicine, 75 Bokji-ro, Busanjin-gu, Busan 614-735, Korea

Tel: +82-51-890-6075, Fax: +82-51-898-9427

E-mail:bkbsur@yahoo.co.kr

(C) 2015 The Korean Society of Coloproctology

This is an open-access article distributed under the terms of the Creative Commons Attribution NonCommercial License (http://creativecommons.org/licenses/by-nc/3.0) which permits unrestricted non-

commercial use, distribution, and reproduction in any medium, provided the original work is properly cited.
uracil/Leucovorin in the Adjuvant Treatment of Colon Cancer) trial reported that the FOLFOX chemotherapeutic regimen, in which oxaliplatin (a third-generation platinum-derivative alkylating agent) was added to 5-fluorouracil (5-FU) and leucovorin (LV), demonstrated a superior disease-free survival (DFS) rate than the LV5FU2 (5-FU and LV regimen) [3]. However, 40\% to $50 \%$ of postsurgical patients with colorectal cancer eventually experienced recurrence and died of metastatic lesions $[4,5]$. Even though the FOLFOX regimen may reduce the risk of recurrence in some patients and increase the survival time, there should be a resistance to oxaliplatin-added chemotherapy in major advanced cases.

Oxaliplatin is a third-generation 1,2-diaminocyclohexane platinum analogue that causes DNA intrastrand crosslinks that trigger a series of intracellular events that ultimately result in cell death $[6$, 7]. However, there are several DNA repair systems in cancer cells, such as the base-excision repair, nucleotide-excision repair (NER), mismatch repair, and double-strand-break repair [8]. Many recent 
studies reported that the NER capacity may have a major impact on the emergence of resistance to the cytotoxic effect of oxaliplatin [9-13]. Especially, a key player and a rate-limiting enzyme of the NER pathway, excision repair cross-complementation group 1 (ERCC1), is closely related to the risk factors of many patients with cancer, including colorectal cancer [14].

Numerous studies have reported that ERCC1 plays a prognostic role in treatment with oxaliplatin-based chemotherapy in patients with metastatic colorectal cancer [15-19]. However, scarce data were reported in an adjuvant setting. The purpose of this study was to identify the risk factors by using ERCC1 for FOLFOX adjuvant chemotherapy in stages II and III colon cancer patients

\section{METHODS}

\section{Subjects}

This is a retrospective, single-armed, observational study with analysis of data prospectively collected from the colorectal cancer registry database. A total of 166 patients were enrolled. They were all colon cancer patients who had been treated with FOLFOX4 adjuvant chemotherapy after a curative resection from April 2006 to December 2010. The colon cancer stage was classified in accordance with the 6th edition of the American Joint Committee on Cancer TNM staging system, and patients with high-risk stage II and III cancer were included in the study. The stage II high-risk group was defined as having at least one of the following factors: stage $\mathrm{T} 4 \mathrm{a} / 4 \mathrm{~b}$ cancer, tumor perforation, bowel obstruction, a poorly differentiated tumor, or venous, perineural, or lymphatic invasion.

\section{Chemotherapy method and follow-up observations}

All the patients were treated with chemotherapy after curative surgery. $\mathrm{LV}$ at $200 \mathrm{mg} / \mathrm{m}^{2} /$ day was administered intravenously for 2 hours. An intravenous bolus of 5 -FU at $400 \mathrm{mg} / \mathrm{m}^{2}$ was then administered, followed by continuous intravenous administration of $5-\mathrm{FU}$ at $600 \mathrm{mg} / \mathrm{m}^{2}$ for the remaining 22 hours. This regimen was continued for 2 days. Oxaliplatin at $85 \mathrm{mg} / \mathrm{m}^{2}$ was infused for 2 hours only on day 1 . A prophylactic antiemetic and sufficient fluid were infused on days 1 and 2 of chemotherapy. The FOLFOX regimen was administered every 2 weeks. The adjuvant chemotherapeutic regimen was carried out for a total of 12 cycles. Patients were followed up every 3 months for the first 2 years after surgery and every 6 months thereafter for 3 years, for a total follow-up period of 5 years.

History taking, physical examination, and measurement of the serum carcinoembryonic antigen (CEA) level were performed at each follow-up visit. Chest $\mathrm{x}$-ray and abdominopelvic computed tomography examinations were performed to assess the efficacy of chemotherapy every four cycles, and every 6 months after completion of chemotherapy. Colonoscopy was performed annually. Recurrence was identified by imaging studies and colonoscopy and was confirmed by colonoscopic or percutaneous biopsy.
Radiologically-identified tumor growth within the previous surgical field was considered to indicate a recurrence when histological confirmation was not possible.

\section{Tissue microarray and immunohistochemistry}

All hematoxylin and eosin-stained slides were reviewed, and the diagnosis of an adenocarcinoma was confirmed. Representative paraffin blocks were selected, and two tissue cores (each $2.0 \mathrm{~mm}$ in diameter) obtained from different parts of the tumor were placed into a recipient paraffin block. Immunohistochemical staining was performed by using antihuman ERCC1 antibody (dilution 1:100: E18550, Spring Bioscience, Pleasanton, CA, USA). Four-micrometer-thick tissue sections from the tissue microarray block were incubated in tris-ethylenediaminetetraacetic acid buffer ( $\mathrm{pH} 8.0)$ and heated at $99^{\circ} \mathrm{C}$ for 30 minutes. After endogenous peroxidase activity had been quenched with $3 \%$ hydrogen peroxide, the sections were treated with a UV inhibitor (Ventana Medical Systems Inc., Tucson, AZ, USA). The sections were incubated with primary antibody at $37^{\circ} \mathrm{C}$ for 30 minutes and then with HRP-multimer (Ventana Medical Systems Inc.) for 8 minutes. Finally, counterstaining was performed with Mayer's hematoxylin. Staining intensity was graded as 1 for weak, 2 for moderate, or 3 for strong, and the percentage of cells stained was graded as 1 for $0 \%$ to $<10 \%, 2$ for $10 \%$ to $<50 \%$, or 3 for $50 \%$ to $100 \%$. Staining for ERCC1 was considered to be positive when tumor cells showed nuclear reactivity and both scores were greater than or equal to 2 (Fig. 1) [20].

\section{Statistical analysis}

All data were presented as count and percentage for discrete variables. The clinical parameters were compared between ERCC1 groups by using the chi-square test or the Fisher exact test, as appropriate. The DFS was analyzed by using the Kaplan-Meier method with the log-rank test. A Cox proportional hazard model with stepwise selection was conducted to identify risk factors for DFS. P-values of $<0.05$ were considered to indicate statistical significance. The statistical analysis was performed by using SAS ver. 9.3 (SAS Institute Inc., Cary, NC, USA).

\section{RESULTS}

\section{Clinical parameters correlated with ERCC1 expression}

The demographic details according to the ERCC1 expression investigated in this study are shown in Table 1. ERCC1-positive expression was detected in 104 patients (ERCC1-positive group), but 62 patients had ERCC1-negative tumors (ERCC1-negative group). The median follow-up time at the time of this analysis was 38.87 months. No significant differences in sex, $\mathrm{T}$ stage, $\mathrm{N}$ stage, histological differentiation, lymphovascular invasion, neural invasion, or postoperative CEA levels were observed between the two groups. However, ERCC1-positive expression was statistically significant in older patients $(\mathrm{P}=0.031)$. Although not statis- 


\section{Coloproctology
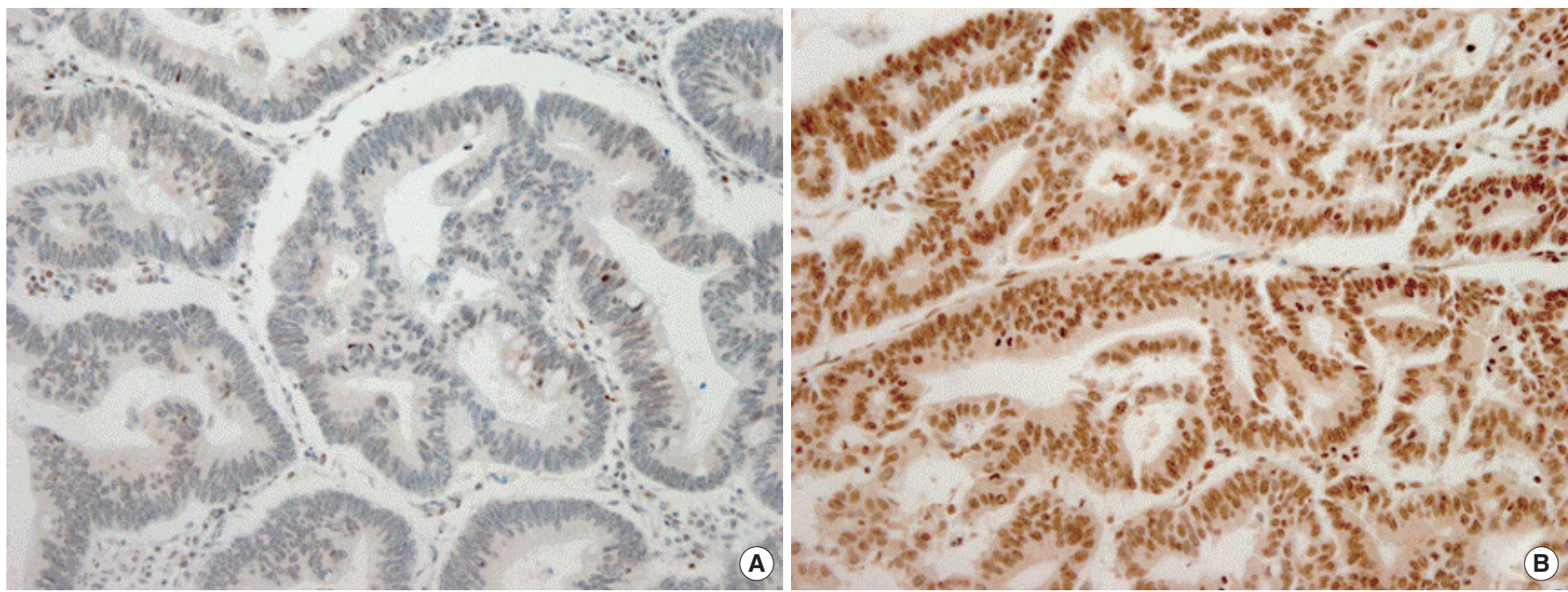

Fig. 1. Immunohistochemical stain for excision repair cross-complementation group $1(\times 200)$ : (A) negative (intensity score 1 , percentage score 1 ) and (B) positive (intensity score 3 , percentage score 3 ).

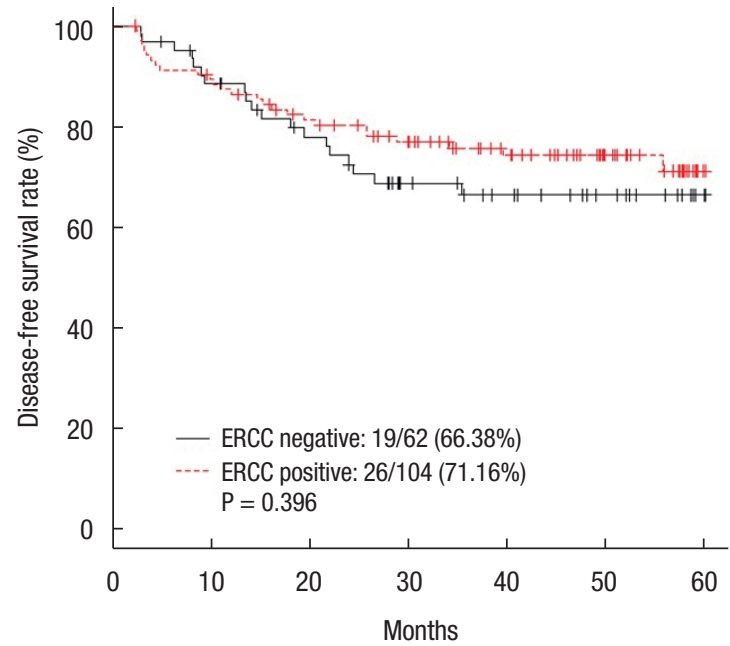

Fig. 2. Five-year disease-free survival rate of all the patients. ERCC, excision repair cross-complementation.

tically significant, ERCC1 expression exhibited a tendency to be elevated in patients with preoperative high CEA levels $(\mathrm{P}=0.095)$ (Table 1).

In both groups, stage T3 tumors (88.55\%) were the most common. Among all patients, stage III tumors (81.93\%) were more common than stage II tumors (18.07\%). In both groups, moderately differentiated tumors $(87.95 \%)$ were the most common. On histopathological examination, lymphovascular invasion was seen in $55(52.88 \%)$ and 34 patients $(54.84 \%)$ in the ERCCI-negative and the ERCC1-positive groups, respectively (Table 1).

\section{Analysis of DFS and prognostic factors}

The 5-year DFS rate was $66.38 \%$ in the ERCC1-negative group

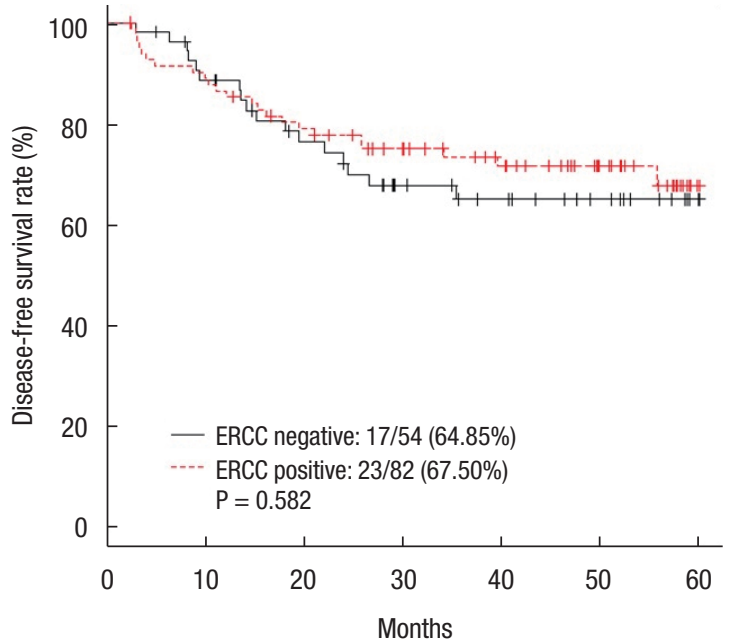

Fig. 3. Five-year disease-free survival rate of stage III patients. ERCC, excision repair cross-complementation.

and $71.16 \%$ in the ERCC1-positive group $(\mathrm{P}=0.396)$ (Fig. 2). The 5 -year DFS rate for patients with stage III disease was not significantly different between the two groups (64.85\% in the negative group and $67.50 \%$ in the positive group, $\mathrm{P}=0.582$ ) (Fig. 3). The 5 -year DFS rate was not significantly associated with the ERCC1 expression in all patients or in those with stage III disease. According to the univariate analysis, the prognostic factors for DFS were female sex $(P=0.047), N$ stage $(P=0.002)$, elevated preoperative CEA level $(\mathrm{P}=0.008)$, and elevated postoperative CEA level $(\mathrm{P}<0.001)$. In the multivariate analysis, the prognostic factors for DFS were female sex $(\mathrm{P}=0.016), \mathrm{N}$ stage $(\mathrm{P}=0.009)$, and postoperative CEA level $(\mathrm{P}=0.001)$ (Table 2). However, ERCC1 expression was not a statistically significant prognostic factor for 
Table 1. Clinical parameters correlated with ERCC1 expression

\begin{tabular}{|c|c|c|c|}
\hline Parameter & Negative $(n=62)$ & Positive $(n=104)$ & P-value \\
\hline Age (yr) & & & 0.032 \\
\hline$\geq 65$ & 38 & 80 & \\
\hline$<65$ & 24 & 24 & \\
\hline Sex & & & 0.660 \\
\hline Male & 33 & 59 & \\
\hline Female & 29 & 45 & \\
\hline T stage & & & 0.582 \\
\hline 1 & 1 & 0 & \\
\hline 2 & 1 & 3 & \\
\hline 3 & 55 & 92 & \\
\hline 4 & 5 & 9 & \\
\hline N stage & & & 0.212 \\
\hline 0 & 8 & 22 & \\
\hline 1 & 33 & 42 & \\
\hline 2 & 21 & 40 & \\
\hline Stage & & & 0.181 \\
\hline$\|$ & 8 & 22 & \\
\hline III & 54 & 82 & \\
\hline Differentiation & & & 0.905 \\
\hline Well & 3 & 3 & \\
\hline Moderately & 54 & 92 & \\
\hline Poorly & 3 & 5 & \\
\hline Mucinous cell & 2 & 3 & \\
\hline Signet-ring cell & 0 & 1 & \\
\hline Lymphovascular invasion & & & 0.807 \\
\hline Absent & 28 & 49 & \\
\hline Present & 34 & 55 & \\
\hline Neural invasion & & & 0.394 \\
\hline Absent & 37 & 55 & \\
\hline Present & 25 & 49 & \\
\hline Preoperative CEA level & & & 0.095 \\
\hline$<5$ & 41 & 55 & \\
\hline$\geq 5$ & 21 & 49 & \\
\hline Postoperative CEA level & & & 0.615 \\
\hline$<5$ & 52 & 84 & \\
\hline$\geq 5$ & 10 & 20 & \\
\hline
\end{tabular}

ERCC1, excision repair cross-complementation group 1; CEA, carcinoembryonic antigen.

DFS in the univariate analysis $(\mathrm{P}=0.397)$ (Table 2$)$.

\section{DISCUSSION}

The FOLFOX chemotherapeutic regimen is commonly used to treat colon cancer and has been shown to be an effective adjuvant
Table 2. Univariate and multivariate analyses of prognostic factors for disease-free survival

\begin{tabular}{|c|c|c|c|}
\hline \multirow{2}{*}{ Classification } & \multirow{2}{*}{$\begin{array}{c}\text { Univariate } \\
\text { P-value }\end{array}$} & \multicolumn{2}{|c|}{ Multivariate } \\
\hline & & $\mathrm{HR}(95 \% \mathrm{Cl})$ & P-value \\
\hline Sex & & & 0.016 \\
\hline \multicolumn{4}{|l|}{ Female } \\
\hline Male & 0.047 & $0.48(0.27-0.87)$ & \\
\hline Age (yr) & & & 0.313 \\
\hline \multicolumn{4}{|l|}{$<65$} \\
\hline$\geq 65$ & 0.337 & $1.238(0.817-1.876)$ & \\
\hline Differentiation & 0.334 & & \\
\hline \multicolumn{4}{|l|}{ Well } \\
\hline \multicolumn{4}{|l|}{ Moderately } \\
\hline Poorly & & & \\
\hline
\end{tabular}

\section{Signet-ring cell}

Mucinous cell

T stage $\quad 0.103$

1

2

3

$4 a$

$4 b$

$\mathrm{N}$ stage

0.002

0.009

0

1

2

$1.11(0.40-3.09)$

$2.83(1.08-7.42)$

Lymphovascular invasion

\begin{tabular}{|c|c|c|}
\hline \multicolumn{3}{|l|}{ Absent } \\
\hline Present & 0.478 & \\
\hline \multicolumn{3}{|c|}{ Neural invasion } \\
\hline \multicolumn{3}{|l|}{ Absent } \\
\hline Present & 0.475 & \\
\hline \multicolumn{3}{|c|}{ Preoperative CEA level } \\
\hline \multicolumn{3}{|l|}{$<5$} \\
\hline$\geq 5$ & 0.008 & \\
\hline \multicolumn{3}{|c|}{ Postoperative CEA level } \\
\hline$<5$ & & Reference \\
\hline$\geq 5$ & $<0.001$ & $2.96(1.59-5.54)$ \\
\hline \multicolumn{3}{|c|}{ ERCC1 expression } \\
\hline \multicolumn{3}{|l|}{ Negative } \\
\hline Positive & 0.397 & \\
\hline
\end{tabular}

$\mathrm{HR}$, hazard ratio; $\mathrm{Cl}$, confidence interval; ERCC1, excision repair cross-complementation group 1; CEA, carcinoembryonic antigen. 
or palliative chemotherapy [3]. However, treatment failure still exists due to a resistance to oxaliplatin, and many patients treated with this regimen develop long-term side effects such as peripheral neuropathy, as well. Thus, surgical oncologists are investigating predictive markers that can influence the oncological outcomes for patients with colon cancer who receive FOL8FOX chemotherapy. ERCC1 is a gene encoding a protein of the NER complex, which is a group of proteins that are able to repair the DNA damage induced by substances forming adducts, such as platinum [13]. Viguier et al. [17] determined the effect of the ERCC1 codon 118 polymorphism on the tumor response of advanced metastatic colorectal cancer treated by using the FOLFOX regimen. Several studies have also shown that ERCC1 expression can be a prognostic factor for cisplatin- or oxaliplatin-based chemotherapy in patients with non-small-cell lung cancer [21], bladder cancer [22], and gastric cancer [23]. Shirota et al. [15] reported a significant correlation between ERCC1 mRNA levels and the survival of patients with unresectable colorectal cancer who received FOLFOX chemotherapy after failure of FOLFIRI chemotherapy $(\mathrm{P}<0.01)$. Kim et al. [20] analyzed ERCC1 by using immunohistochemistry in 50 patients with colorectal cancer with unresectable metastases that had been treated with the FOLFOX regimen and reported that the median overall survival was significantly longer in patients without ERCC1 expression $(\mathrm{P}=0.047)$. However, our data showed no significant association between the 5-year DFS and ERCC1 expression in patients with high-risk stages II and III colon cancer treated with FOLFOX adjuvant chemotherapy, not even in subgroup analysis with stage III colon cancer.

This study has some notable limitations. First, the sample size was too small to access reliably the association between ERCC1 expression and DFS. Thus, more studies with larger sample sizes are required. Second, the ERCC1 expression level was investigated only though immunohistochemistry without polymerase chain reaction for mRNA expression. Third, no further evaluations were done with thymidylate synthase expression or k-ras status, so this potential prognostic factor must be investigated in future studies.

Interestingly, Li et al. [24] reported a similar outcome to that of the current study. They determined that the mRNA expression level of ERCC1 was not significantly associated with the DFS in Chinese patients with stage II to III colorectal cancer who received 5-FU and oxaliplatin-based adjuvant chemotherapy; neither did they find a significant association between DFS and thymidylate synthase. On the other hand, another study of patients with stage III colon cancer who received oxaliplatin-based adjuvant chemotherapy reported that the 5-year DFS was significantly higher in patients with ERCC1-negative tumors (72\%) than in patients with ERCC1-positive tumors (54\%) (hazard ratio, 1.98; 95\% confidence interval, 1.19-3.31; $\mathrm{P}=0.009$ ) [25].

Although ERCC1 expression was not a statistically significant prognostic factor for DFS in this study, we found that lymphnode metastasis and a high postoperative CEA level were signifi- cant prognostic factors of 5-year DFS in patients with colon cancer with high-risk stages II and III disease treated with FOLFOX adjuvant chemotherapy. Several studies have demonstrated that lymph-node metastasis could be a prognostic factor for stage III colorectal cancer treated with FOLFOX adjuvant chemotherapy $[26,27]$. Additionally, many studies have shown that abnormal postoperative CEA levels are significantly associated with postoperative relapse [28, 29]. Huang et al. [29] reported that a higher postoperative CEA level was a prognostic factor in patients with stage III colorectal cancer who received FOLFOX4 chemotherapy. Therefore, the node stage and the postoperative CEA level should be considered in future studies that perform prognostic analyses of FOLFOX adjuvant chemotherapy for treating patients with colorectal cancer.

In conclusion, we found that ERCC1 expression was not significantly correlated with the 5 -year DFS as reflected by the oncologic outcomes in patients with high-risk stages II and III colon cancer treated with FOLFOX adjuvant chemotherapy. Nevertheless, several studies have reported various outcomes regarding the prognostic correlation between ERCC1 expression and FOLFOX chemotherapy in an adjuvant setting. Therefore, a prospective, randomized, controlled trial that includes both ERCC1 and variable biomarkers is needed.

\section{CONFLICT OF INTEREST}

No potential conflict of interest relevant to this article was reported.

\section{ACKNOWLEDGMENTS}

The bio-specimens and data used in this study were provided by the Inje University Busan Paik Hospital, a member of the Korea Biobank Network.

\section{REFERENCES}

1. Jung KW, Park S, Won YJ, Kong HJ, Lee JY, Seo HG, et al. Prediction of cancer incidence and mortality in Korea, 2012. Cancer Res Treat 2012;44:25-31.

2. National Comprehensive Cancer Network clinical practice guidelines in oncology (NCCN Guidelines): Colon/rectal cancer. ver. 3. 2013 [Internet]. Fort Wathington: National Comprehensive Cancer Network; c2015 [cited 2015 Jan 10]. Available from: http:// www.nccn.org/professionals/physician_gls/f_guidelines.asp..

3. Andre T, Boni C, Mounedji-Boudiaf L, Navarro M, Tabernero J, Hickish T, et al. Oxaliplatin, fluorouracil, and leucovorin as adjuvant treatment for colon cancer. N Engl J Med 2004;350:2343-51.

4. Obrand DI, Gordon PH. Incidence and patterns of recurrence following curative resection for colorectal carcinoma. Dis Colon Rectum 1997;40:15-24.

5. O'Connell JB, Maggard MA, Ko CY. Colon cancer survival rates 
with the new American Joint Committee on Cancer sixth edition staging. J Natl Cancer Inst 2004;96:1420-5.

6. Scheeff ED, Briggs JM, Howell SB. Molecular modeling of the intrastrand guanine-guanine DNA adducts produced by cisplatin and oxaliplatin. Mol Pharmacol 1999;56:633-43.

7. Giacchetti S, Perpoint B, Zidani R, Le Bail N, Faggiuolo R, Focan C, et al. Phase III multicenter randomized trial of oxaliplatin added to chronomodulated fluorouracil-leucovorin as first-line treatment of metastatic colorectal cancer. J Clin Oncol 2000;18:136-47.

8. Goode EL, Ulrich CM, Potter JD. Polymorphisms in DNA repair genes and associations with cancer risk. Cancer Epidemiol Biomarkers Prev 2002;11:1513-30.

9. Raymond E, Faivre S, Chaney S, Woynarowski J, Cvitkovic E. Cellular and molecular pharmacology of oxaliplatin. Mol Cancer Ther 2002;1:227-35.

10. Goodisman J, Hagrman D, Tacka KA, Souid AK. Analysis of cytotoxicities of platinum compounds. Cancer Chemother Pharmacol 2006;57:257-67.

11. Gossage L, Madhusudan S. Current status of excision repair cross complementing-group 1 (ERCC1) in cancer. Cancer Treat Rev 2007;33:565-77.

12. Rabik CA, Dolan ME. Molecular mechanisms of resistance and toxicity associated with platinating agents. Cancer Treat Rev 2007;33:9-23.

13. Martin LP, Hamilton TC, Schilder RJ. Platinum resistance: the role of DNA repair pathways. Clin Cancer Res 2008;14:1291-5.

14. Moreno V, Gemignani F, Landi S, Gioia-Patricola L, Chabrier A, Blanco I, et al. Polymorphisms in genes of nucleotide and base excision repair: risk and prognosis of colorectal cancer. Clin Cancer Res 2006;12(7 Pt 1):2101-8.

15. Shirota Y, Stoehlmacher J, Brabender J, Xiong YP, Uetake H, Danenberg KD, et al. ERCC1 and thymidylate synthase mRNA levels predict survival for colorectal cancer patients receiving combination oxaliplatin and fluorouracil chemotherapy. J Clin Oncol 2001;19:4298-304.

16. Stoehlmacher J, Park DJ, Zhang W, Yang D, Groshen S, Zahedy S, et al. A multivariate analysis of genomic polymorphisms: prediction of clinical outcome to 5-FU/oxaliplatin combination chemotherapy in refractory colorectal cancer. Br J Cancer 2004;91:344-54.

17. Viguier J, Boige V, Miquel C, Pocard M, Giraudeau B, Sabourin JC, et al. ERCC1 codon 118 polymorphism is a predictive factor for the tumor response to oxaliplatin/5-fluorouracil combination chemotherapy in patients with advanced colorectal cancer. Clin Cancer Res 2005;11:6212-7.

18. Ruzzo A, Graziano F, Loupakis F, Rulli E, Canestrari E, Santini D, et al. Pharmacogenetic profiling in patients with advanced colorectal cancer treated with first-line FOLFOX-4 chemothera- py. J Clin Oncol 2007;25:1247-54.

19. Balin-Gauthier D, Delord JP, Pillaire MJ, Rochaix P, Hoffman JS, Bugat R, et al. Cetuximab potentiates oxaliplatin cytotoxic effect through a defect in NER and DNA replication initiation. Br J Cancer 2008;98:120-8.

20. Kim SH, Kwon HC, Oh SY, Lee DM, Lee S, Lee JH, et al. Prognostic value of ERCC1, thymidylate synthase, and glutathione Stransferase pi for 5-FU/oxaliplatin chemotherapy in advanced colorectal cancer. Am J Clin Oncol 2009;32:38-43.

21. Lord RV, Brabender J, Gandara D, Alberola V, Camps C, Domine $\mathrm{M}$, et al. Low ERCC1 expression correlates with prolonged survival after cisplatin plus gemcitabine chemotherapy in non-small cell lung cancer. Clin Cancer Res 2002;8:2286-91.

22. Bellmunt J, Paz-Ares L, Cuello M, Cecere FL, Albiol S, Guillem V, et al. Gene expression of ERCC1 as a novel prognostic marker in advanced bladder cancer patients receiving cisplatin-based chemotherapy. Ann Oncol 2007;18:522-8.

23. Kwon HC, Roh MS, Oh SY, Kim SH, Kim MC, Kim JS, et al. Prognostic value of expression of ERCC1, thymidylate synthase, and glutathione S-transferase P1 for 5-fluorouracil/oxaliplatin chemotherapy in advanced gastric cancer. Ann Oncol 2007;18: 504-9.

24. Li P, Fang YJ, Li F, Ou QJ, Chen G, Ma G. ERCC1, defective mismatch repair status as predictive biomarkers of survival for stage III colon cancer patients receiving oxaliplatin-based adjuvant chemotherapy. Br J Cancer 2013;108:1238-44.

25. Li S, Zhu L, Yao L, Xia L, Pan L. Association between ERCC1 and TS mRNA levels and disease free survival in colorectal cancer patients receiving oxaliplatin and fluorouracil (5-FU) adjuvant chemotherapy. BMC Gastroenterol 2014;14:154.

26. Kim SH, Shin SJ, Lee KY, Kim H, Kim TI, Kang DR, et al. Prognostic value of mucinous histology depends on microsatellite instability status in patients with stage III colon cancer treated with adjuvant FOLFOX chemotherapy: a retrospective cohort study. Ann Surg Oncol 2013;20:3407-13.

27. Uncu D, Aksoy S, Cetin B, Yetisyigit T, Ozdemir N, Berk V, et al. Results of adjuvant FOLFOX regimens in stage III colorectal cancer patients: retrospective analysis of 667 patients. Oncology 2013;84:240-5.

28. Filiz AI, Sucullu I, Kurt Y, Karakas DO, Gulec B, Akin ML. Persistent high postoperative carcinoembryonic antigen in colorectal cancer patients: is it important? Clinics (Sao Paulo) 2009;64:287-94.

29. Huang MY, Tsai HL, Lin CH, Huang CW, Ma CJ, Huang CM, et al. Predictive value of ERCC1, ERCC2, and XRCC1 overexpression for stage III colorectal cancer patients receiving FOLFOX-4 adjuvant chemotherapy. J Surg Oncol 2013;108:457-64. 